\title{
O parto "natural" e "humanizado" na visão de mulheres de camadas médias e populares no Rio de Janeiro
}

\author{
"Natural" and "humanized" childbirth in the perspective of \\ middle class and poor women in Rio de Janeiro
}

Olivia Nogueira Hirsch*

\begin{abstract}
Resumo: Nesse artigo, fruto de uma pesquisa de doutorado, pretende-se compreender os significados atribuídos ao parto "humanizado" por mulheres provenientes de diferentes camadas sociais. O trabalho incluiu entrevistas e observação participante em dois universos, ambos na cidade do Rio de Janeiro: uma casa de parto pública e um curso privado de preparação para o parto, oferecido por uma ativista da ReHuNa. Os dados colhidos sugerem que as mulheres de camadas médias investigadas dão grande valor à redução das intervenções médicas de rotina e à sensação corporal, que é considerada uma via para o aperfeiçoamento subjetivo. Já para as entrevistadas de camadas populares, o que mais se valoriza na proposta é o tratamento dispensado pelos profissionais de saúde que trabalham na casa parto e o fato de serem reconhecidas como "pessoas" e não apenas como um corpo que dá à luz, como costuma ocorrer nas maternidades públicas brasileiras.
\end{abstract}

Palavras-chave: Parto humanizado. Camadas populares. Camadas médias.

Abstract: This paper, part of a $\mathrm{PhD}$ research, aims to understand the meanings given by women from different social classes to the so called "humanized birth". The investigation included interviews and fieldwork in two places, both of them in the city of Rio de Janeiro: in a public birth center and in a private pre-natal course, offered by a $\mathrm{ReHuNa}$ activist. The results suggest that middle class women give special importance to the reduction in pharmacological intervention and to the body experience, considered to provide a subjective growth. The poor women value specially the way in which they are treated by the nurses/midwives that work in the birth center and the fact that there they are treated as people, not only as a body that gives birth, as usually happens in public maternities in Brazil.

Keywords: Humanized birth. Poor class. Middle class.

\footnotetext{
* Doutora em Ciências Sociais pela Pontifícia Universidade Católica do Rio de Janeiro (PUC-Rio, Rio de Janeiro, RJ, Brasil), professora do departamento de Ciências Sociais da PUC-Rio <olivianh@gmail.com>.
}

Civitas, Porto Alegre, v. 15 , n. 2, p. 229-249, abr.-jun. 2015 


\section{Apresentação}

O movimento pela "humanização" do parto e do nascimento surgiu no Brasil entre as décadas de 1980 e 1990, a partir de uma crítica, iniciada dentro do próprio campo da obstetrícia, ao modelo hegemônico de assistência ao parto, considerado excessivamente medicalizado e tecnocrático. Com iniciativas esparsas e, em geral, restritas ao setor privado, a proposta de oferecer um atendimento "mais respeitoso" à mulher e ao bebê ganhou a adesão de um pequeno segmento de mulheres de camadas médias, ainda que o nome "humanização" não fosse utilizado.

A institucionalização do movimento ocorreu em 1993, com a fundação da Rede pela Humanização do Parto e do Nascimento (ReHuNa). Esta assumiu como meta o incentivo à redução de intervenções médicas de rotina, ao partir do pressuposto de que o parto deveria resultar de um processo "natural" e fisiológico. Para a organização, que reconhece a relação interpessoal como um importante componente da assistência, o parto "humanizado" teria como premissas: o "protagonismo" da mulher, a valorização do vínculo entre a mãe e o bebê e o compromisso com uma medicina baseada em evidências (MBE). ${ }^{1}$

Com o passar dos anos, o movimento pela "humanização" do parto e do nascimento, que encontra respaldo em um conjunto de recomendações divulgado pela Organização Mundial da Saúde sobre tecnologias adequadas ao parto, expandiu-se e ganhou reconhecimento. Aos poucos, os membros da ReHuNa começaram a ter acesso às instâncias governamentais - como consultores ou integrando seus quadros oficiais -, vindo a contribuir para o desenvolvimento de políticas públicas. Não demorou muito para que mulheres de camadas populares, usuárias do Sistema Único de Saúde (SUS), passassem a dar à luz em unidades públicas de saúde identificadas como "humanizadas".

No Rio de Janeiro, uma das instituições assim reconhecidas pela ReHuNa é a casa de parto (CP), ${ }^{2}$ que foi inaugurada em 2004, época em que um grupo de

\footnotetext{
${ }^{1}$ Diniz (2005) realizou um estudo no qual buscou compilar alguns dos diversos, e às vezes conflitantes, sentidos atribuídos ao termo "humanização" por parte dos diferentes atores sociais. Em sua pesquisa, realizada em duas maternidades que se autoclassificam como "humanizadas", a autora constatou que a expressão apareceu como: sinônimo de MBE - a partir da noção de que a atuação médica não deve ser orientada pela tradição -; "respeito aos direitos (reprodutivos e sexuais, ao acesso universal e ao consumo de tecnologia); tratamento acolhedor e respeitoso; manejo da dor do parto e a prevenção da dor iatrogênica; novas atribuições profissionais e disputas corporativas; relação custo-benefício etc." (Diniz, 2005, p. 627). A pesquisa de Diniz aponta, portanto, para a diversidade de significados atribuídos ao termo "humanização", que tem sido objeto de disputa e negociação, à medida que seu uso se dissemina.

${ }^{2}$ Em artigo (Rattner, Santos, Lessa, Diniz, 2010), membros da ReHuNa classificam a implantação da CP como um dos primeiros "projetos concretos de humanização" e um "modelo para atenção em Centros de Parto Normal (CPN) extra-hospitalares do país".
} 
feministas esteve à frente da Secretaria Municipal de Saúde. A CP se localiza em um bairro popular na Zona Oeste da cidade e a assistência ao pré-natal, parto e puerpério nessa unidade de saúde pública é prestada exclusivamente por enfermeiras obstetras.

Ao longo dos anos 2000, com a internet cada vez mais acessível, mulheres de camadas médias passaram a criar listas de discussão na internet e sites de apoio à "humanização", o que contribuiu para a disseminação da proposta dentro desse segmento, em especial nos grandes centros urbanos.

Nesse artigo, pretende-se analisar como dois grupos de mulheres do Rio de Janeiro, provenientes de diferentes camadas sociais, recebem e atualizam a proposta de parto "humanizado". Enquanto em décadas anteriores a tendência era a de universalizar as mulheres e suas experiências, mais recentemente a ênfase dos estudos de gênero tem recaído sobre as diferenças que podem ser mapeadas entre elas. Com efeito, este foi o enfoque do presente estudo, que parte da premissa de que a classe interfere na forma como os sujeitos enxergam o mundo, podendo, portanto, influenciar a maneira como as mulheres significam e vivenciam a experiência de parturição. Vale destacar que, em diferentes contextos, essa premissa também norteou os trabalhos de Martin (2006), Nelson (1983), Davis-Floyd (1994), Zadoroznyj (1999) e Johnson (2008).

No cenário brasileiro, importantes referências foram os estudos das antropólogas Carmen Susana Tornquist (2003; 2004) e Rosamaria Carneiro (2011). Em uma pesquisa de fôlego, Tornquist investigou o movimento pela "humanização" do parto no Brasil, ao fazer uma etnografia da ReHuNa, com vistas a compreender suas formas de organização e ideário. Além disso, a pesquisadora realizou trabalho de campo em dois cursos de capacitação de parteiras tradicionais, em Minas Gerais, e em uma maternidade pública de Florianópolis, que atende principalmente mulheres de camadas populares, mas também uma parcela proveniente de camadas médias.

Já Carneiro (2011) direcionou sua atenção para as experiências de parto "humanizado" entre mulheres de camadas médias, tendo feito etnografia em dois grupos de preparo para o parto em São Paulo. Segundo a pesquisadora, que procurou travar um diálogo com o feminismo, entre as mulheres investigadas predominavam diferentes concepções de pessoa, saúde, dor e risco.

O estudo pioneiro de Tania Salem (2007), realizado na década de 1980, foi outra referência central. A autora pesquisou o fenômeno então designado de "casal grávido", tomando como foco casais provenientes das camadas médias do Rio de Janeiro. Segundo Salem, a expressão denotava a participação do homem já na gravidez e no parto, bem como o compromisso do casal com 
o propósito de que o parto fosse realizado com um mínimo de interferência médica. A autora analisou o ideal igualitário presente no ideário da época e também os dilemas enfrentados pelos casais no período pós-parto. Ainda que o termo "humanização" não fosse utilizado, é possível notar muitas semelhanças entre a proposta de parto "natural" dos anos 1980 e o ideário da "humanização" - tal como difundido pelos ativistas da ReHuNa -, o que atesta a importância e atualidade do estudo de Salem.

\section{Em campo}

A pesquisa incluiu observação participante, bem como entrevistas semiestruturadas com 38 gestantes e puérperas. Destas, 12 eram integrantes de um grupo privado de preparação para o parto na Zona Sul do Rio de Janeiro, que é coordenado por Flora, uma doula ${ }^{3}$ que também é ativista da ReHuNa (Grupo 1), e 26 vinculadas ao pré-natal da CP, instituição pública de saúde, à qual já foi feito referência (Grupo 2). ${ }^{4}$

O contato com Flora se deu no início dos anos 2000, ocasião em que ela atuou como doula no parto de minha irmã. A despeito desse contato prévio, notei certa relutância de sua parte em franquear acesso às aulas do curso quando, anos mais tarde, a procurei por conta da pesquisa. A sensação era de que ela não estava muito segura quanto a meu posicionamento sobre o ideário.

Se com Flora houve algum tipo de resistência inicial, o contato com as mulheres do grupo, por sua vez, transcorreu de forma suave e espontânea. A gravidez, sem dúvida, nos aproximou muito, para além das semelhanças sociais de classe, cor, etc., as quais já compartilhávamos. Todas manifestavam grande interesse em dividir suas experiências e percepções, o que se refletia nas entrevistas, que costumavam ser longas e ricas em detalhes. Na realidade, eu me percebia com as mesmas dúvidas e anseios que as mulheres do grupo e, a partir de então, o desafio era tentar construir algum distanciamento, ainda que limitado e provisório, que me permitisse refletir sobre o observado/ sentido/vivido. Nesse aspecto, a decisão de fazer um estudo comparativo se mostrou quase estratégica: ela viria a tornar menos árdua a tarefa de buscar desnaturalizar o olhar das mulheres de camadas médias para o assunto.

A primeira visita que fiz à $\mathrm{CP}$ demonstrou que a decisão era, de fato, acertada: o perfil das mulheres que a frequentavam era bastante diverso,

\footnotetext{
3 "Mulher treinada e com experiência em nascimentos, que provê suporte físico, emocional e informacional à mulher e sua família durante o trabalho de parto, parto e pós-parto" (Fadynha, 2003, p. 9). Doula é uma das especialistas que surgiram no esteio do movimento pela "humanização" do parto e do nascimento.

${ }^{4}$ As entrevistas foram realizadas entre os anos de 2011 e 2012.
} 
o que certamente enriqueceria a pesquisa. A gravidez ajudou a gerar uma identificação, nesse caso, contribuindo para superar as distâncias sociais que nos separavam. No entanto, o interesse em participar da pesquisa em geral não era o mesmo e as entrevistas costumavam ser mais curtas e objetivas - o que explica a diferença no que se refere ao número de entrevistadas de cada grupo.

Entre os profissionais da CP foi possível notar certo estranhamento por se tratar de uma investigação em Antropologia. Ainda assim, tinham a expectativa de que a pesquisa, de alguma maneira, pudesse contribuir para valorização e reconhecimento do trabalho desenvolvido, em meio ao intenso monitoramento por parte do Conselho Regional de Medicina do Rio de Janeiro (Cremerj) - fruto de uma disputa mais ampla por campos de atuação.

\section{Grupo 1: O curso de preparação para o parto na Zona Sul e o perfil das mulheres}

O curso de preparação para o parto "natural" e "humanizado", 5 onde foi realizada a pesquisa, é um dos poucos na cidade a oferecer esse tipo de serviço. Dentre as frequentadoras, há gestantes de diferentes bairros, que se matricularam ali depois de terem feito uma ampla pesquisa - principalmente na internet - em busca desse tipo de parto. Outras, no entanto, moram na região e chegam ao local porque desejam fazer alguma atividade física de baixo impacto durante a gestação ou mesmo em busca de aliviar o estresse do dia-adia. Estas acabam conhecendo a proposta de parto ao longo das aulas e, muitas delas, aderem ao projeto. É importante destacar que um número expressivo de frequentadoras do curso é composto por estrangeiras que moram no Brasil e tomaram conhecimento dos altos índices de cesariana no país. Elas buscam o instituto com o objetivo de instrumentalizarem-se para o parto "normal", 6 que têm como referência em seus países de origem. Com efeito, dentre as entrevistadas, uma parcela possui nacionalidades alemã e francesa.

Com idades entre 28 e 42 anos, a maior parte das entrevistadas é casada, vive apenas com o marido ou com o marido e o(s) filho(s) e tem renda familiar acima de 10 salários mínimos. Elas apresentam alta escolaridade: à exceção de

\footnotetext{
${ }_{5}^{5}$ Os significados atribuídos a esses termos pelas mulheres entrevistadas e por profissionais que se identificam como "humanizados", com os quais tive contato durante a pesquisa, serão explorados ao longo do artigo.

${ }^{6} \mathrm{Na}$ segunda metade do século 20, o modelo hospitalar expandiu-se e tornou-se o padrão de assistência nos centros urbanos da maioria dos países. De acordo com Diniz (2005), surgia naquele momento o modelo de parto "normal" até hoje em vigor: com o uso de drogas para regulação do trabalho de parto e parto; imobilização total ou parcial da parturiente, em posição de litotomia; proibição de ingerir líquidos ou alimentos por via oral e com a abertura cirúrgica da musculatura da vulva e da vagina - episiotomia - como procedimento de rotina.
} 
uma, todas concluíram o ensino superior e quase a metade também fez cursos de pós-graduação e mestrado, estando a maior parte inserida no mercado de trabalho formal. Uma parcela expressiva atua em empresas do setor público, como BNDES e Petrobrás. Com efeito, as profissões das entrevistadas podem ser divididas em dois grupos: aquelas que atuam nas chamadas "áreas exatas", como administradora, economista, engenheira civil e professora de matemática, ${ }^{7}$ e as de "áreas humanas", como tradutora, fotógrafa, professora de dança, professora de artes etc. No que se refere à religião, quase a metade declara não ser adepta de qualquer denominação.

A maior parte das entrevistadas estava grávida pela primeira vez ou tinha recentemente dado à luz o primeiro filho, em sua maioria fruto de uma gravidez planejada - algumas com até 2 ou 3 anos de antecedência. Além disso, à exceção de uma, todas possuem planos de saúde. No entanto, apenas uma foi assistida por um obstetra conveniado na hora de dar à luz, apesar de quase a metade ter iniciado o pré-natal com um médico vinculado ao plano de saúde. Foi decisivo para isso o contato com uma proposta de parto classificada como "humanizada" durante o curso e a informação transmitida ali - e diversas vezes confirmada por relatos das próprias mulheres - de que, de maneira geral, os médicos conveniados a planos de saúde dão preferência aos partos cesáreos. Segundo elas, aqueles, em menor número, que não são "cesaristas" e se dispõem a acompanhar partos vaginais, costumam seguir o modelo medicalizado de assistência e há inclusive casos de obstetras que cobram uma taxa extra para fazer esse tipo de acompanhamento, alegando que o valor repassado pelos planos de saúde é muito baixo.

\section{Parto como experiência}

Ainda que em momento algum as entrevistadas do Grupo 1 se identifiquem como feministas, 9 a visão que a maioria tem do parto "natural" e "humanizado" aparentemente é influenciada por esse olhar. Com frequência, os discursos sugerem que esse tipo de parto é valorizado justamente por respeitar a mulher. Respeito, na visão das entrevistadas, em geral, significa ter suas escolhas em relação ao parto acolhidas pelo obstetra ou ser consultada previamente, caso isso não seja possível. Esse tipo de interação, que prevê um diálogo entre

\footnotetext{
${ }^{7}$ É interessante notar que esse dado difere bastante daquele observado por Salem nos anos 1980. $\mathrm{Na}$ época, os "casais grávidos", adeptos do "parto natural", tinham uma "certa inclinação para escolher carreiras menos convencionais, no sentido de mais à margem do sistema" (Salem, 2007, p. 143).

8 Termo êmico.

${ }^{9}$ É interessante notar que Carneiro (2011) chegou à constatação semelhante em pesquisa com mulheres de camadas médias adeptas do parto "humanizado" em São Paulo.
} 
médico e paciente, estabelece um relacionamento igualitário entre as partes, que não costuma marcar esse tipo de relação. A equidade na relação com o profissional de saúde, segundo algumas entrevistadas, abre caminho para que a mulher possa ter controle sobre seu corpo durante o trabalho de parto e parto. Nesse sentido, a desmedicalização aparece nos relatos como condição necessária para que a parturiente possa assumir o controle e ocupar o papel de "protagonista", que teria sido usurpado pelos obstetras em meio ao uso rotineiro de drogas e à realização de procedimentos médicos, como costuma ocorrer no parto "normal".

A minha definição de humanizado é criar, para a parturiente, uma situação que permita que ela seja a dona do parto, não é? [...] Dona do parto é poder contar com as próprias forças para parir, próprias forças fisiológicas. Na verdade, é a confiança na mulher, não é? A equipe de profissionais deve ter confiança na mulher, não é? Confiança, para mim, é a palavra chave. (Andréa) ${ }^{10}$

A segunda médica [com quem me consultei] faz bastante parto normal até, só que esse normal convencional. Ela não é humanizada. E eu conversei com ela, eu queria saber como ela via o parto. Então eu perguntei: "mas como é que é o parto?" E ela me descreveu assim, palavras dela: "o parto é tranquilo. Você vai começar a sentir as contrações e você vai estar na maternidade, vão colocar um soro na tua veia, vão colocar anestesia para que você não sinta dor, vou chegar e vou fazer um toque, vou ver o tamanho da dilatação e aí vou fazer a episiotomia, porque é preciso fazer e vou te dirigir. Vou falar para você: "não, faz força agora. Não faz." Então percebe que é um parto normal que não é normal. Normal é só no nome, porque você sai totalmente da figura mais importante da situação. Você é tida como a figura que está sendo ajudada pela médica nesse caso. Então eu me sentiria muito invadida de ter que fazer coisas que estão sendo ditas para mim que é o certo. "Faz isso, porque agora tem que ser feito isso." E no parto humanizado, pelo menos comigo foi assim, nada foi imposto para mim. Eu fazia o que eu tinha vontade de fazer. Eu ficava nas posições que eu tinha vontade de ficar. Eu entrava ou saía da banheira na hora em que eu tinha vontade. Enfim, então eu vejo dessa maneira. (Silvana)

[O parto humanizado] é aquele que a mulher tem voz e poder de escolha. É o protagonismo, é o que ela decide. Aquele é o corpo dela. Existe a tecnologia, existe, mas tudo dentro de um limite de escolha da mulher. Onde ela quer parir, de que forma ela quer parir e ser respeitada por isso. Não entrar em um sistema que trata todas

\footnotetext{
${ }^{10}$ Os nomes das entrevistadas foram substituídos por outros, para garantir o anonimato.
} 
como iguais. É padrão, é padrão para todas. Não, cada uma é cada uma, cada trabalho de parto, cada vivência de dor cada uma vai ter a sua. Nós somos iguais, mas somos individualizados. Cada uma deve ter esse poder de decisão e ser respeitada por isso. É o protagonismo dela mesmo. (Vanessa)

Como é possível notar, as entrevistadas procuram reafirmar o controle sobre seus corpos, o que conduz à ideia de que o parto, uma experiência inegavelmente física e carnal, deve ser sobretudo fruto de suas escolhas, ${ }^{11}$ assim como o foi a opção pela maternidade, como atesta a maior parte das entrevistadas do grupo. Segundo observou Carneiro, o discurso feminista e seus slogans "o meu corpo me pertence" e "o pessoal é político" sugerem operar como pano de fundo desses discursos, que aparentemente se veem "atravessado[s] pelas ondas igualitaristas e diferencialistas, coadunando direitos de igualdade e de singularidade" (Carneiro, 2011, p. 278).

Os depoimentos chamam a atenção para a ênfase dada à liberdade e ao reconhecimento das singularidades, sendo possível dizer que o ideário se encontra atravessado pelo processo de individualização, subjacente à lógica de modernização dos comportamentos sociais, que predomina entre os segmentos médios da sociedade brasileira. Nesse sentido, é possível afirmar que as entrevistadas desse grupo almejam ser reconhecidas como "indivíduos", com liberdade e autonomia para decidir sobre seus partos. ${ }^{12}$ Além de acreditarem que a medicalização transfere ao médico o controle sobre o processo, as mulheres também rejeitam esse recurso alegando que ele padroniza experiências que, a depender da fisiologia, seriam muito diversas.

A possibilidade de manifestação das diferenças, segundo essa perspectiva, estaria atrelada à ausência de intervenções - termo frequentemente utilizado pelas mulheres do Grupo 1 para se referir à atuação médica e que, em geral, assume uma conotação negativa. Sobre essa questão, é importante destacar as nuances no que se refere aos significados atribuídos aos termos parto "natural" e "humanizado". Profissionais de saúde com quem mantive contato e mesmo algumas entrevistadas de camadas médias os diferenciam, afirmando que parto

\footnotetext{
${ }^{11}$ As escolhas, muitas vezes construídas a partir do repertório apresentado nas aulas de preparação, em geral referem-se à posição de parto, ao local onde se dará à luz (se maternidade, domicílio ou casa de parto), ao tipo de assistência, ao uso ou não de medicação para dor etc. Em resumo, as escolhas representam um questionamento do modelo hegemônico de parturição: hospitalar, em posição de litotomia, com assistência de um obstetra e medicação de rotina, sem que a mulher seja consultada, isto é, sem que se leve em conta sua individualidade, como costuma ocorrer no chamado parto "normal".

${ }^{12}$ De fato, Franchetto, Cavalcanti e Heilborn (1981) argumentam que o feminismo - que teve forte influência no movimento pela "humanização" - é, na prática, um desdobramento do individualismo.
} 
"natural" é aquele no qual não há qualquer tipo de intervenção, isto é, que depende exclusivamente da fisiologia do corpo feminino, e "humanizado" aquele em que a mulher tem suas escolhas respeitadas. A depender dessas escolhas, é possível haver uma sobreposição, no caso, por exemplo, das que manifestam o desejo de não ter um parto medicalizado. Mas, segundo essa mesma visão, também é considerado "humanizado" o parto que respeita o desejo de se tomar anestesia ou de se fazer uma cesárea, caso a mulher esteja ciente dos benefícios e riscos envolvidos nessa escolha.

No entanto, durante as entrevistas, a maioria das mulheres desse grupo, ao expressar o que entendia por parto "humanizado", referiu-se à ausência de intervenções, algumas delas assinalando, dentre as motivações que as levaram a optar por esse tipo de parto, a preferência pelo "natural". Esta preferência manifestou-se em comentários tais como: "é como a natureza criou a mulher", "não há o que ser escolhido ou decidido, é o natural", "[o parto] é a expressão mais fantástica da natureza, do milagre da vida, de uma coisa que é supernatural", dentre outros.

É possível notar a partir desses comentários uma ideia de natureza norteando o olhar dessas mulheres sobre o parto "humanizado", o que faz com que o termo parto "natural" seja utilizado quase que de maneira intercambiável. Vale destacar que, para as entrevistadas, a natureza manifesta-se principalmente através do corpo que, sob essa ótica, estaria imune às influências da cultura. O corpo é visto como perfeito, detentor de um conhecimento inato e de uma temporalidade própria, que devem ser respeitados. De outra feita, esse conhecimento estaria ameaçado, pois as tecnologias poderiam comprometer a percepção, as sensações e, o mais grave, interferir no funcionamento do corpo, que é visto como apto e capaz de dar à luz.

O corpo em questão, por certo, não é um corpo qualquer: trata-se do corpo feminino, que é valorizado por suas potencialidades, dentre elas a reprodução biológica. Nesse sentido, a crítica ao determinismo biológico, tão vocalizada em um primeiro momento pelas feministas, que atribuíam à reprodução o confinamento das mulheres ao espaço privado e à dominação masculina (Scavone, 2001), não parece ser problematizada pelo grupo. Pelo contrário. Aparentemente em sintonia com a corrente do feminismo identificada como diferencialista, ${ }^{13}$ que busca a afirmação das diferenças e da identidade feminina, a maternidade é "considerada como um poder insubstituível, o qual só as mulheres possuem" (Scavone, 2001, p. 141). Assim, de "handicap" ou "defeito natural", a maternidade passa a ser valorizada e positivada.

\footnotetext{
${ }^{13}$ Para uma discussão aprofundada sobre o tema ver: Carneiro (2011).
} 
É interessante destacar que o mesmo parece ocorrer em relação ao parto: outrora encarado como sacrifício ou fonte de sofrimento, ele passa a ser percebido como um desafio, como algo que desperta curiosidade. Assim, não é de chamar a atenção que o interesse em vivenciar o trabalho de parto $\mathrm{e}$ suas sensações corporais surjam praticamente como um denominador comum entre as entrevistadas. Uma delas, por exemplo, usou diversas vezes o verbo "curtir" para referir-se ao trabalho de parto. Mãe de três filhos nascidos no Brasil, Andréa, que é alemã e vive em união estável com um brasileiro, narrou os partos como uma trajetória de aperfeiçoamento da experiência. O relato do parto do último filho, que ela julga ter sido o que lhe rendeu mais satisfação, sugere que seu foco era o processo de parturição, a experiência, e não apenas o nascimento em si:

O trabalho de parto que é tudo. É uma preparação. O clímax é o nascimento [...]. Na hora, eu falei: "Eu consegui!” Mas logo eu falei: "Conseguimos! Obrigada, Senhor, por ter essa sensação! Conseguimos, eu e ele [o filho]! Conseguimos!”.

Vários aspectos poderiam ser destacados desse relato, contudo, gostaria de enfatizar apenas um deles: a satisfação manifestada por Andréa - e também por outras entrevistadas do grupo - por ter experimentado a "sensação" de parir. Com efeito, em uma análise acerca da sensibilidade ocidental nos dias atuais, Duarte destaca que as inúmeras estratégias de maximização da vida e otimização do corpo - dentre as quais situa justamente a ginecologia e a anestesia -, foram resultado da sistemática exploração do corpo "como sede da busca indefinida, eternamente perfectível, da exacerbação da sensibilidade, do refinamento ou intensificação do prazer" (Duarte, 1999, p. 27). De fato, afirma o autor, a busca constante por um aprofundamento das intensidades é uma marca do hedonismo moderno, o que faz com que experiências sensoriais novas sejam valorizadas na medida em que, de alguma maneira, são percebidas como acrescentando algo ao sujeito, isto é, representam uma via de aperfeiçoamento.

Assim, sugiro que a experiência de parto "natural" e "humanizado" entre mulheres de camadas médias seja analisada com base nessas reflexões. Com efeito, a possibilidade de vivenciar um parto sem qualquer tipo de "intervenção" é valorizada também enquanto experiência física, isto é, por suas sensações, as quais a mulher pode ter acesso apenas poucas vezes na vida. A intensidade da experiência está atrelada à ausência de medicamentos, em grande medida da anestesia, pois esta representa justamente a perda, ainda que parcial, da sensibilidade. 
Eu acho que o parto é uma experiência muito intensa, muito importante na vida da mulher e eu quero passar por isso assim... tentar sentir o máximo disso, extrair o máximo dessa experiência. (Tatiana)

[O meu incômodo no primeiro parto foi] Não sentir, assim, era não saber... É como se fosse assim, é o que eu falo para as pessoas: um filme que eu tinha o início e o fim, que é quando você recebe o bebê, mas aquele meio ficou faltando. [...] Eu falei assim: "Bom, se eu estou no parto, eu quero sentir o parto. Porque eu vou estar fazendo um negócio e vou estar eliminando a sensação que aquela coisa ali me dá? (Alice)

Eu me senti muito realizada no meu primeiro parto, mas ficou essa dúvida: como é que teria sido se eu não tivesse tomado anestesia? E dessa segunda vez eu falei assim: "Nossa! Eu quero ir além. Eu quero sentir tudo. Eu quero dar o máximo”. (Angélica)

Os depoimentos apontam para o desejo de vivenciar o parto da maneira mais "natural" possível, isto é, sem nada que reduza ou minimize as sensações que o acompanham. A intensidade, em especial das emoções - seja da dor ou da alegria - é valorizada, pois, segundo as mulheres, justamente dela advém a riqueza da experiência. ${ }^{14}$ Vale destacar que a vivência das novas sensações possibilitadas pelo parto é frequentemente considerada transformadora, como afirma a entrevistada Kátia, que se considera outra pessoa depois de dar à luz:

Essa força [do parto] fica com a gente, sabe? [...] Hoje em dia eu me sinto muito mais intuitiva. Estou agora querendo abrir duas empresas. Estou criando isso. Estou com muito mais força para isso, sabe? Mesmo tendo bebê pequeno, mesmo dormindo menos. Quer dizer, é uma força que fica, que te acompanha para sempre e teu filho faz parte disso. E quando você reduz a discussão a parto normal versus cesariana, dor a não dor, é um absurdo tão grande, porque você está reduzindo, você está banalizando a questão. (Kátia)

Como sugere o relato de Kátia, assim como o parto de maneira geral, a dor, de maneira particular, também é ressignificada pela maioria das entrevistadas. Algumas inclusive evitam fazer uso da palavra para referir-se às sensações do trabalho de parto, dando preferência a termos como "força",

\footnotetext{
${ }^{14}$ Observação semelhante foi feita por Carneiro (2011). Segundo a autora, entre as participantes dos grupos que investigou havia "o desejo de afetação, o desejo das dores e das sensações, para elas, responsáveis pela intensidade da experiência” (Carneiro, 2011, p. 193).
} 
"pressão" e "coisas". De maneira geral, as mulheres argumentam tratar-se de uma dor "diferente", que deve ser vista como positiva, pois tem um objetivo, um resultado, não sendo comparável à dor provocada por uma doença ou lesão. Uma entrevistada afirmou, nesse sentido, que trata-se de uma dor "amiga", uma vez que dela, isto é, da contração, depende o nascimento do bebê. Em resumo, as mulheres do Grupo 1 buscam apontar as especificidades das sensações, tentando atribuir um novo significado à dor que acompanha as contrações, fora do registro do sofrimento, que tradicionalmente rege a visão que se tem sobre o parto em nossa sociedade.

As observações de Le Breton auxiliam a compreender o processo vivido por essas mulheres. De acordo como autor, a forma como o sujeito se relaciona com a dor depende do significado que atribui a ela. Tal significado, longe de ser unívoco, é fruto de um "entremeado" que se constrói a partir da "manera en que el hombre se apropia de la cultura, de unos valores que son los suyos, de su relación con el mundo" (Le Breton, 1999, p. 9).

É interessante notar que, em diversas sociedades tradicionais, a dor acompanha os ritos de passagem, ${ }^{15}$ atestando a transição de um universo social a outro, isto é, alterando a antiga relação que o sujeito mantinha com o mundo à sua volta. É também uma marca de pertencimento, ao gerar uma identificação entre aqueles que, submetidos ao mesmo ritual, são capazes de resistir às dores e superar as adversidades por ele impostas.

No que se refere às mulheres investigadas, a experiência de parto pode ser também compreendida como parte de um rito de passagem, encarado como necessário e enriquecedor do ponto de vista subjetivo, o que favorece a ressignificação da dor por elas operada. Nesse sentido, o parto é vivido como uma exibição de força, resistência e consolidação da feminilidade, servindo de base para a construção de uma identificação entre aquelas que se dispuseram e foram capazes de superar as dores provocadas pelas contrações sem recorrer a medicamentos. ${ }^{16}$

\section{Grupo 2: A casa de parto na Zona Oeste e o perfil das mulheres}

O segundo grupo que compõe esse estudo, referido como Grupo 2, é formado por mulheres que frequentavam a $\mathrm{CP}$, localizada no subúrbio do Rio de Janeiro. Esta unidade pública de saúde atende exclusivamente gestantes

\footnotetext{
${ }^{15}$ Segundo Van Gennep (1978), trata-se de "ritos que acompanham toda mudança de lugar, estado e posição social de idade".

${ }^{16}$ Para mais informações sobre essa discussão, ver Hirsch (2014).
} 
classificadas como de "baixo risco"17 e a assistência ao parto é realizada por enfermeiras obstetras.

A maioria das entrevistadas é de moradoras da região, que chegaram após terem ouvido comentários positivos sobre a $\mathrm{CP}$, mas com poucas informações sobre as particularidades do serviço. Elas acabaram tomando conhecimento da proposta de parto - nesse contexto quase sempre referido apenas como parto "natural", tanto pelas mulheres quanto pelos profissionais ${ }^{18}$ - durante o "Acolhimento", encontro coletivo no qual a diretora apresenta o lugar e seu projeto, mas também ao longo das consultas e dos grupos educativos, obrigatórios durante o pré-natal.

Com idades entre 14 e 38 anos, a maior parte se identificou como solteira, categoria em que se incluíram muitas das que, na prática, viviam em união estável. Ainda que a maioria tenha informado residir com o marido/parceiro ou com o marido/parceiro e filhos, quase $1 / 3$ residia também com a família de origem, uma realidade bastante diversa das entrevistadas do Grupo 1.

Considerando que a maior parte dos atendimentos do SUS se concentra em usuários com faixa de renda entre $1 / 4$ e 1/2 salário mínimo (Ipea, 2011), é possível que as mulheres que integram a pesquisa façam parte de uma "elite" dentro do segmento popular, tendo em vista que a maioria apresentou renda familiar entre 2 e 5 salários mínimos e foi registrado apenas um caso de integrante do Programa Bolsa Família.

Assim como a renda, também chama a atenção naquele contexto o nível de escolaridade das entrevistadas: a maior parte completou o ensino médio. No entanto, a escolaridade relativamente alta não se traduziu em engajamento no mercado de trabalho, já que a maioria declarou-se "do lar". Destas, contudo, $1 / 3$ era de estudantes que abandonaram a escola por conta da gravidez. Em menor número, as entrevistadas que trabalhavam assumiam ocupações variadas, tais como: operadora de caixa, auxiliar de serviços operacionais, secretária, pastora, comerciante e manicure. No que se refere à religião, mais da metade declarou ser evangélica.

\footnotetext{
${ }^{17}$ A palavra risco encontra-se entre aspas por entender que a noção de risco é relativa, podendo variar significativamente entre os diversos segmentos e grupos da sociedade. A definição baixo risco, nesse caso específico, atende a critérios estabelecidos por um rígido protocolo médico, elaborado à época da inauguração do local e que é submetido a constantes revisões.

${ }^{18}$ É importante destacar que o termo parto "humanizado" era desconhecido por muitas das entrevistadas e, entre aquelas familiarizadas com ele, poucas se sentiam à vontade para defini-lo. Ainda assim, durante todo o período em que foi realizada a pesquisa de campo havia uma faixa na porta de entrada do local, que informava: "Parir e nascer com dignidade e humanização". Já os profissionais que trabalham ali afirmavam que o atendimento prestado é "humanizado", ainda que poucas vezes fizessem referência ao termo quando se dirigiam às mulheres.
} 
Assim como no outro grupo, a maioria das entrevistadas estava grávida pela primeira vez ou tinha recentemente dado à luz o primeiro filho. No entanto, a maior parte não havia planejado a gravidez. De acordo com os depoimentos, para uma parcela expressiva a gestação foi recebida com um grande "susto", quando não com "desespero" e "tristeza". Isso fez com que a gravidez fosse vivida por muitas como um período de "aceitação" ou mesmo de "superação".

\section{Parto bom é parto rápido}

Se para o Grupo 1 passar pela experiência de parto "natural" e "humanizado" implica em um grande envolvimento por parte da gestante, para a maioria das entrevistadas do Grupo 2 a proposta de desmedicalização em si não desperta grande interesse. ${ }^{19}$ Assim como ocorre com a gestação, a proposta de parto é "aceita" ao longo das consultas do pré-natal e dos grupos educativos, que foram criados justamente para sensibilizar as gestantes e sua família. $\mathrm{O}$ forte investimento da $\mathrm{CP}$ na transmissão do ideário - são 8 grupos, com cerca de $2 \mathrm{~h}$ de duração cada - se justifica pelo fato de que a mulher que dá à luz ali deve aderir integralmente ao projeto, havendo pouca margem para negociação.

Mas se não é pela proposta de parto, o que as leva a optar por dar à luz ali? Com base nas entrevistas, é possível afirmar que o grande atrativo da CP é a interação que se estabelece com os profissionais de saúde, no caso, as enfermeiras obstetras e auxiliares de enfermagem, as quais não raras vezes as mulheres passam a considerar "amigas" ou mesmo parte da família. Nesse sentido, a maioria das entrevistadas respondeu que a qualidade do atendimento foi o que mais valorizaram na instituição. ${ }^{20}$ Os adjetivos usados para qualificar o "tratamento" recebido não foram poucos: educado, atencioso, carinhoso, amigável, familiar, receptivo, dedicado, hospitaleiro, paciente etc. Noutras palavras, o que as mulheres mais valorizam na CP é a possibilidade de serem tratadas como "pessoas" (DaMatta, 1997), reconhecidas em sua individualidade, com um nome, uma história e sendo percebidas como envoltas em redes sociais mais amplas.

\footnotetext{
${ }^{19}$ Constatação semelhante foi feita por Tornquist (2004) durante pesquisa realizada em uma maternidade pública em Florianópolis. Segundo a autora, para as mulheres de classes populares a forma do parto não assumia a centralidade observada entre aquelas provenientes de camadas médias.

${ }^{20}$ Bosi e Affonso (1998), que realizaram pesquisa em cinco unidades públicas de serviços básicos no município do Rio de Janeiro, também observaram a importância atribuída pelos usuários de camadas populares à qualidade da relação com o profissional de saúde.
} 
Uma coisa que me chamou bastante atenção foi eles [na casa de parto] saberem, assim, chamar a gente pelo nosso nome, né? Porque nos hospitais geralmente não tem isso, esse tratamento. Até mesmo a primeira doutora, ela se lembrava de mim. Quando eu chegava para as outras consultas, ela vinha e falava comigo. Então, eu achei isso, assim, bastante gratificante. (Jussara)

Como é possível notar, a $\mathrm{CP}$ desponta como uma alternativa às maternidades públicas, por onde, em experiências anteriores, passaram muitas das entrevistadas. A avaliação dessas experiências costuma ser bastante negativa, em especial no que se refere ao tratamento dispensado pelos profissionais. $^{21}$

Os médicos e os enfermeiros das maternidades são muito ignorantes. A gente não pode falar um "ai" que eles: "Vocês estão acostumadas já, tem que sofrer para ter neném!” Eu acho que eles podiam ser mais humanos com a gente... (Mariana)

O hospital, que é para te trazer tranquilidade, para mim me traz pavor. Você pergunta uma coisa e eles te tratam muito mal, te deixam muito jogada. (Vanuza)

Mas se as mulheres não poupam críticas ao tratamento dispensado nas maternidades e hospitais, o mesmo não se pode dizer do parto medicalizado, tal qual costuma ser realizado no sistema público de saúde. Para muitas delas, os procedimentos médicos são valorizados enquanto formas de cuidado e considerados uma "ajuda". O corte no períneo, tecnicamente chamado de episiotomia, é um deles. Este procedimento amplia a abertura da região vulvo-perineal na hora do parto, o que facilita a saída do bebê. Além disso, também costuma ser visto como uma garantia de que a mulher preservará a integridade da vagina após o parto. O temor é de que o órgão sexual feminino seja "rasgado" ou fique "frouxo" e "largo" depois da passagem do bebê. Deve-se ressaltar que esta crença é difundida até mesmo nos manuais de Obstetrícia, o que sugere que o corpo feminino é percebido mesmo por muitos profissionais de saúde como imperfeito e dependente de sua atuação.

\footnotetext{
${ }^{21}$ Os maus tratos sofridos durante o parto também foram reportados pelas entrevistadas de McCallum e Reis (2006), em pesquisa com adolescentes de classes populares numa maternidade pública de Salvador.
} 
Por outro lado, na CP a informação de que a "vagina é um órgão elástico" e que depois retorna ao seu tamanho normal é repetida diversas vezes ao longo das consultas e dos grupos educativos, com o intuito de aplacar a preocupação expressa pelas mulheres, quando informadas de que o "corte" termo nativo para se referir à episiotomia - não é feito de rotina como nas maternidades.

Outra prática realizada nos partos em hospitais públicos e que as mulheres naquele contexto costumam avaliar como positiva é a administração de ocitocina sintética, a que chamam de "soro". Esse medicamento tem como objetivo acelerar as contrações uterinas o que, em última instância, acelera o trabalho de parto. Os efeitos da ocitocina sintética parecem ir ao encontro do desejo das entrevistadas, uma vez que muitos relatos dão conta de que o parto considerado "bom" é aquele que termina "rápido", ou seja, aquele em que a parturiente passa pouco tempo em trabalho de parto, ainda que as dores sejam classificadas como muito intensas. Nesse sentido, é possível afirmar que as mulheres naquele contexto desejam "superar" o processo de parturição - assim como ocorre com a gravidez -, e não desfrutá-lo e vivenciá-lo, como mencionaram as entrevistadas do Grupo 1.

Deve-se destacar que situação semelhante foi observada por Nelson (1983) em pesquisa com mulheres de camadas populares nos Estados Unidos da América, o que levou a autora a afirmar que o acesso à tecnologia é um privilégio de classe e que, para rejeitar a medicalização, é preciso antes tê-la desfrutado:

That class of women who have always had access to the most sophisticated medical technology may make the decision to reject some aspects of that class privilege; those who have not yet consistently received these benefits may not be ready to abandon them. (Nelson, 1983, p. 295-296)

Também a dor, que durante a gestação despertou curiosidade e foi encarada como desafiadora pelas entrevistadas de camadas médias, foi percebida de maneira diversa pelas mulheres do Grupo 2. Estas, durante a gravidez, em geral manifestaram medo do parto e, depois de terem vivido a experiência, com frequência a classificaram como "horrível". Um aspecto importante a se destacar é que, se entre as parturientes do Grupo 1 a decisão de não tomar anestesia foi fruto de uma escolha (que pode ser modificada ao longo do processo), no caso das mulheres de camadas populares não se tratou de opção, mas de contingência. E isso não se restringe à realidade da $\mathrm{CP}$. Nas maternidades e hospitais públicos a oferta de anestesia para as situações de parto "normal" é extremamente 
reduzida, ${ }^{22}$ fazendo com que muitas mulheres de camadas populares sequer saibam da possibilidade de se tomar medicação para alívio da dor durante o trabalho de parto, como se constatou durante a pesquisa.

No entanto, é importante ressaltar que, por mais que não tenha sido fruto de uma escolha, a dor também foi ressignificada pela maioria das puérperas do Grupo 2. Nesse sentido, a análise das entrevistas aponta que, apesar de enfatizada, a descrição da dor costuma ser acompanhada de uma conjunção adversativa, que a minimiza. Assim, a dor foi definida como "horrível", mas "suportável"; "depois você esquece dela"; "para imediatamente depois que o bebê nasce"; "aumenta aos poucos".

Da mesma forma, ainda que a possibilidade de assumir o controle sobre o processo não seja algo valorizado e nem tenha sido o que as levou até ali, algumas entrevistadas e seus familiares enfatizaram, depois da experiência de parto, a importância da atuação da mulher ao dar à luz de modo desmedicalizado:

Ali [na hora do parto], dependia de mim para a minha filha nascer, não é? Se demorasse mais um pouco, poderia até acontecer alguma coisa com ela.

Entrevistadora: Então você sente que no parto natural depende mais de você?

É. Totalmente. (Eliane)

Quando começou o trabalho de parto, aí já era ela [Joana], não é? Era ela praticamente que ia exercer a coisa ali, fazer acontecer. (Antônio, marido de Joana)

O da menina doeu, mas o do menino, aqui na casa de parto, a dor foi maior. Porque aqui a gente tem um trabalho... aquele trabalho nosso. Porque não tem aquele corte [...]. Na hora de botar para fora teve a dor de empurrar e foi muito mais difícil. Mas o dela não, porque o dela já estava tudo aberto. Não tinha nada empatando ela nascer. (Roberta, comparando o parto da primeira filha, na maternidade e com episiotomia, ao do segundo filho, nascido na CP.)

De diferentes formas, os relatos sugerem que a experiência de parto "natural" e "humanizado", tal como proposta na CP, acabou por exigir que

\footnotetext{
${ }^{22}$ Resultados da pesquisa "Nascer no Brasil: inquérito nacional sobre parto e nascimento" apontam que a anestesia foi aplicada em apenas $27 \%$ das entrevistadas que deram à luz em hospitais públicos (Leal et al., 2014). A sondagem contou com uma amostra de 24 mil mulheres, de 191 municípios e 266 diferentes estabelecimentos de saúde (públicos e privados), contemplando todos os estados do país.
} 
as mulheres assumissem uma participação mais ativa e se percebessem como fundamentais no processo de parturição, em comparação com situações nas quais procedimentos de rotina são realizados, como em maternidades e hospitais públicos.

\section{Considerações finais}

Apesar das muitas diferenças observadas entre os dois grupos investigados, em parte tributárias da diferença de classe - sem dúvida essencial para se compreender a visão de mundo dos sujeitos -, é também possível apontar algumas semelhanças entre eles.

Nesse sentido, pode-se dizer que as mulheres etnografadas de ambos os grupos buscam modelos alternativos por revelarem uma insatisfação com as práticas relativas ao parto e nascimento, às quais, como regra, têm acesso. Essa insatisfação, em geral, está associada ao fato de as mulheres sentirem-se, de alguma maneira, desrespeitadas.

No entanto, se para um grupo esta percepção se constrói a partir da crítica à medicalização excessiva - especialmente predominante no sistema de saúde privado - que padroniza experiências e não reconhece na parturiente um "indivíduo", com liberdade e autonomia para fazer escolhas sobre os procedimentos que serão realizados em seus corpos, para o outro o questionamento advém do tratamento dispensado pelo profissional de saúde da rede pública. A estes acusam de não reconhecerem na parturiente uma "pessoa", para além do corpo que dá à luz. Sem nome, identidade, história e às vezes na "solidão" de uma enfermaria coletiva - tendo em vista que ainda hoje algumas instituições rejeitam a presença de acompanhantes, a despeito da existência de leis que a preveem - essas mulheres dão à luz, com medo e em silêncio, temendo desagradar profissionais de saúde atentos apenas à anatomia e à fisiologia, isto é, à chamada "máquina do corpo". Em suma, enquanto para as mulheres do Grupo 1 o que se almeja é ser reconhecida como "indivíduo", para as mulheres do Grupo 2, o que se busca é ser reconhecida como "pessoa". ${ }^{23}$

Com referenciais de contraste diversos, as motivações que conduzem ao parto "natural" e "humanizado" são também diversas. Nesse sentido, é possível dizer que para muitas mulheres de camadas populares a proposta de parto desmedicalizado não costuma ser desejada. Ela é, de certa maneira, a

\footnotetext{
${ }^{23}$ É importante destacar que a penetração do individualismo não foi homogênea, sendo possível dizer que dentro de uma mesma sociedade, por exemplo, há grupos que se mostram mais resistentes a essa ideologia, como é o caso daqueles que vivem em áreas rurais ou os que integram as chamadas camadas populares, aparentemente menos abertos à sua influência.
} 
moeda de troca que aceitam "pagar" para serem reconhecidas e tratadas como "pessoas". Para tanto, concordam em abrir mão da desejada medicalização, a qual teriam acesso em hospitais e maternidades públicos, onde o "corte" e o "soro" são administrados de rotina. Como exposto, tais procedimentos são, de maneira geral, considerados uma "ajuda", pois favorecem que o trabalho de parto transcorra mais rapidamente, o que naquele contexto soa quase como definição de "bom parto". Nesse sentido, o foco dessas mulheres parece estar no resultado, isto é, no nascimento do bebê.

No outro grupo, por sua vez, a ênfase recai sobre o processo, isto é, sobre o trabalho de parto em si, e não apenas sobre o parto. O interesse está em "curtir" o processo, em sentir as contrações, ou seja, em viver o parto e desfrutar a intensidade de emoções e sensações que essa experiência, que acreditam ter um potencial transformador, pode proporcionar.

A despeito das diferenças acima registradas, algumas mulheres de camadas populares parecem, ao fim e ao cabo, vivenciar experiências semelhantes daquelas almejadas pelas parturientes de camadas médias. Em meio à (indesejada) ausência de procedimentos de rotina, elas têm a sensação de que o nascimento de seus filhos resulta de sua atuação e esforço. Noutras palavras, compartilham da sensação de que o parto, tal como proposto na $\mathrm{CP}$, depende primordialmente delas. Para estas, portanto, o parto é vivido como um rito de passagem cujo período liminar tem como marca a "individualização" (DaMatta, 1999) - uma experiência temporária e transitória, mas nem por isso menos transformadora.

\section{Referências}

BOSI, Maria Lúcia Magalhães; AFFONSO, Kátia de Carvalho. Cidadania, participação popular e saúde: com a palavra os usuários da Rede Pública de Serviços. Cadernos de Saúde Pública, v. 14, n. 2, p. 355-365, 1998.

CARNEIRO, Rosamaria Giatti. Cenas de parto e políticas do corpo: uma etnografia de práticas femininas de parto humanizado. Campinas, 2011. Tese de doutorado em Ciências Sociais, Universidade Estadual de Campinas.

DINIZ, Carmen Simone Grilo. Humanização da assistência ao parto no Brasil: os muitos sentidos de um movimento. Ciência \& Saúde Coletiva, v. 10, n. 3, p. 627-637, 2005.

DUARTE, Luiz Fernando Dias. O império dos sentidos: sensibilidade, sensualidade e sexualidade na cultura ocidental moderna. In: Maria Luiza Heilborn (Org.). Sexualidade: o olhar das ciências sociais. Rio de Janeiro: Jorge Zahar Editor, 1999. p. 21-30.

DAMATTA, Roberto. Carnavais, malandros e heróis: para uma sociologia do dilema brasileiro. 6. ed. Rio de Janeiro: Rocco, 1997. 
DAMATTA, Roberto. Individualidade e liminaridade: considerações sobre os ritos de passagem e a modernidade. Mana, v. 6, n. 1, p. 7-29, 2000.

DAVIS-FLOYD, Robbie. The technocratic body: American childbirth as cultural expression. Social Science and Medicine, v. 38, n. 8, p. 1125-1140, 1994.

FADYNHA. A doula no parto: o papel da acompanhante de parto especialmente treinada para oferecer apoio contínuo físico e emocional à parturiente. São Paulo: Editora Ground, 2011.

FRANCHETTO, Bruna; CAVALCANTI, Maria Laura; HEILBORN, Maria Luiza. Antropologia e feminismo. In: Bruna Franchetto; Maria Laura Cavalcanti; Maria Luiza Heilborn (Orgs.). Perspectivas antropológicas da mulher. v. 1. Rio de Janeiro: Zahar Editores, 1981. p. 11-47.

HIRSCH, Olivia. O parto "natural" e "humanizado": um estudo comparativo entre mulheres de camadas populares e médias no Rio de Janeiro. Rio de Janeiro, 2014. Tese de doutorado em Ciências Sociais, Pontifícia Universidade Católica do Rio de Janeiro.

IPEA. Retrato das desigualdades de gênero e raça. Brasília: Ipea, 2011.

JONHSON, Candace. The political "nature" of pregnancy and childbirth. Canadian Journal of Political Science, v. 41, n. 4, p. 889-913, 2008.

LEAL, Maria do Carmo; PEREIRA, Ana Paula Esteves; DOMINGUES, Rosa Maria Soares Madeira; FILHA, Mariza Miranda Theme; DIAS, Marcos Augusto Bastos; NAKAMURA-PEREIRA, Marcos; BASTOS, Maria Helena; GAMA, Silvana Granado Nogueira. Intervenções obstétricas durante o trabalho de parto e parto em mulheres brasileiras de risco habitual. Cadernos de Saúde Pública, v. 30, supl. 1, p. S17-S32, 2014.

LE BRETON, David. Antropología del dolor. Barcelona: Editorial Seix Barral, 1999.

MARTIN, Emily. A mulher no corpo: uma análise cultural da reprodução. Rio de Janeiro: Garamond, 2006.

MCCALUM, Cecília; REIS, Ana Paula. Re-significando a dor e superando a solidão: experiências do parto entre adolescentes de classes populares atendidas em uma maternidade pública de Salvador, Bahia, Brasil. Cadernos de Saúde Pública, v. 22, n. 7, p. 1483-1491, 2006.

NELSON, Margaret K. Working-class women, middle class women, and models of childbirth. Social problems, v. 30, n. 3, p. 284-297, 1983.

RATTNER, Daphne; SANTOS, Marcos Leite dos; LESSA, Heloisa; DINIZ, Simone Grilo. ReHuNa - a Rede pela Humanização do Parto e Nascimento. Revista Tempus: Actas de Saúde Coletiva, v. 4, n. 4, p. 215-228, 2010.

SALEM, Tania. O casal grávido: disposições e dilemas da parceria igualitária. Rio de Janeiro: Editora FGV, 2007.

SCAVONE, Lucila. A maternidade e o feminismo: diálogo com as ciências sociais. Cadernos Pagu, v. 16, p. 137-150, 2001.

TORNQUIST, Carmen S. Paradoxos da humanização em uma maternidade no Brasil. Cadernos de Saúde Pública, v. 19, n. 2, p. S419-S427, 2003. 
TORNQUIST, Carmen S. Parto e poder: o movimento pela humanização do parto no Brasil. Florianópolis, 2004. Tese de doutorado em Antropologia Social, Universidade Federal de Santa Catarina.

VAN GENNEP, Arnold. Os ritos de passagem. Petrópolis: Vozes, 1978.

ZADOROZNYJ, Maria. Social class, social selves and social control in childbirth. Sociology of Health \& Illness, v. 21, n. 3, p. 267-289, 1999.

Recebido em: $1^{\circ}$ jul. 2014

Aprovado em: 12 jan. 2015

Autora correspondente:

Olivia Nogueira Hirsch

PUC-Rio

Departamento de Ciências Sociais

Rua Marquês de São Vicente, 225 - Gávea

22451-900 - Rio de Janeiro, RJ 